Increased rates of suicide in farmers have been a cause for concern in agricultural circles in the recent past and are attributed largely to declining incomes. As well as direct financial worries, inclement weather, burgeoning bureaucracy and greater work load have all been cited by farmer's leaders as stressors. Current disquiet includes the possible effects of the export ban on live animals, and bovine spongiform encephalopathy (BSE) on returns.

In response to this crisis, local branches of the Farmers Union of Wales and the National Farmers Union, in collaboration with the Citizens' Advice Bureau and Samaritans, have commissioned an information leaflet and confidential advice line. While this initiative can only be applauded, it is uncertain whether the most vulnerable individuals will make contact and seek help. Past experience in less well defined target populations has not been promising (e.g. Kreitman \& Chowdhury, 1973). Moreover, as a group farmers are traditionally noted for their stoicism and self-sufficiency, and are often isolated socially and geographically. Their relatively easy access to firearms should not be forgotten.

Suicide prevention is a feasible objective as pointed out by eminent authorities elsewhere (Hawton \& Morgan, 1993). General practitioners and psychiatrists need to keep informed of putative trends if serendipitous contacts with members of high risk groups are to be exploited for averting suicide.

HAWTON, K. \& MORGAN, H.G. (1993) Suicide prevention by general practitioners. British Journal of Psychiatry, 162. 422.

KREMMNN, N. \& CHOWDHURY, N. (1973) Distressed behaviour: a study of selected Samaritan clients and parasuicide ('attempted suicide patients'). British Journal of Psychiatry, 123, 1-8.

The Country Times \& Express \& Gazette, 16 September 1994. p2.

KeVIn Nichous, Keele Rotation, City General Hospital, Stoke-on-Trent, Staffordshire ST4 6QG

\section{AIDS education}

Sir: Dr Treloar (Psychiatric Bulletin, January 1995, 19, 52) notes that I congratulate a Brazilian newspaper for promoting the message that "sex is good for physical and mental health" and quotes me as saying that sex is "safe with a condom". The first quote is correct but the second is not, what the newspaper actually said was "wear a condom", and this is how the quote appeared in my article. I doubt anyone would argue that condoms are "safe", but as the WHO study shows they are safer than doing nothing. Short of not having sex, there is still no measure that is completely safe. Safe-sex, or more accurately safer-sex, campaigns aim to give information on how to reduce risks and this was the message of the Brazilian newspaper.

The question of condom failure is a complex one. While the pores in condoms may allow leakage of HIV, whether this alone is sufficient to cause infection is less clear. Bodily fluids such as tears and saliva also contain HIV, but at levels which are not believed to be infective. Condom failure is often due to the condom coming off during intercourse or to tearing, which has little or nothing to do with its porosity. Some brands of condom are coated with the spermicide nonoxynol-9, which is viricidal and safe sex campaigns recommend its use with condoms so as to further reduce the risk of transmission. Anecdotal reports from Brazil suggest that some people are unaware that condoms cannot be used with oll-based lubricants, adding further to the risk of condom failure.

JoHn DuNn, Departamento de Psiquiatria, Escola Paulista de Medicina, São Paulo-SP, 04023-900, Brazil

\section{'An induction day for trainees in psychiatry'}

Sir: Dr McLaren and colleagues (Psychiatric Bulletin, 1994, 18, 687-688) have presented a lucid account of the rationale behind the organisation of their trainees' induction day. This was of particular interest to me, as I had just helped to organise both local and regional induction days in SW Thames. Their description serves to highlight some of the difficulties which I faced in designing an appropriate programme.

I would strongly endorse the principle of serving "the trainees, the clinical tutor and the personnel department" but it may prove awkward to fulfil all these aims simultaneously. Often there is an unspoken conflict between issues of service provision 